\title{
Functional connectivity and alterations in baseline brain state in humans
}

\author{
Roberto Martuzzi ${ }^{\text {a,*}}$, Ramachandran Ramani ${ }^{\mathrm{b}}$, Maolin Qiu ${ }^{\mathrm{a}}$, Nallakkandi Rajeevan ${ }^{\mathrm{a}}$, R. Todd Constable ${ }^{\text {a,c,d }}$ \\ a Department of Diagnostic Radiology, Yale University School of Medicine, New Haven CT, USA \\ b Department of Anesthesiology, Yale University School of Medicine, New Haven CT, USA \\ ' Department of Biomedical Engineering, Yale University School of Medicine, New Haven CT, USA \\ d Department of Neurosurgery, Yale University School of Medicine, New Haven CT, USA
}

\section{A R T I C L E I N F O}

\section{Article history:}

Received 8 June 2009

Revised 10 July 2009

Accepted 15 July 2009

Available online 22 July 2009

\section{Keywords:}

Anesthesia

Functional connectivity

Functional magnetic resonance imaging

Low-sensory areas

Thalamus

Insula

Hippocampus

Default mode network

\begin{abstract}
A B S T R A C T
This work examines the influence of changes in baseline activity on the intrinsic functional connectivity fMRI (fc-fMRI) in humans. Baseline brain activity was altered by inducing anesthesia (sevoflurane end-tidal concentration 1\%) in human volunteers and fc-fMRI maps between the pre-anesthetized and anesthetized conditions were compared across different brain networks. We particularly focused on low-level sensory areas (primary somatosensory, visual, and auditory cortices), the thalamus, and pain (insula), memory (hippocampus) circuits, and the default mode network (DMN), the latter three to examine higher-order brain regions. The results indicate that, while fc-fMRI patterns did not significantly differ $(p<0.005 ; 20$-voxel cluster threshold) in sensory cortex and in the DMN between the pre- and anesthetized conditions, fc-fMRI in high-order cognitive regions (i.e. memory and pain circuits) was significantly altered by anesthesia. These findings provide further evidence that fc-fMRI reflects intrinsic brain properties, while also demonstrating that 0.5 MAC sevoflurane anesthesia preferentially modulates higher-order connections.
\end{abstract}

(c) 2009 Elsevier Inc. All rights reserved.

\section{Introduction}

Functional areas in the brain are highly interconnected, creating networks that allow complex processing of external and/or internal stimulus representations. To understand how the brain works it is necessary to study not only the brain regions involved in a given task but also how different functional areas of the brain are connected.

In their seminal work, Biswal et al. (1995), showed that during rest the blood oxygenation level dependent (BOLD) signal exhibits phaselocked low-frequency oscillations $(<0.1 \mathrm{~Hz})$ across functionally connected brain regions. This observation allowed the definition of a new method for studying non-invasively functional connectivity within the brain that is now referred to as functional connectivity fMRI (fc-fMRI). The vast majority of the fc-fMRI studies have been focused on the motor/somatosensory (e.g. Biswal et al., 1995; Cordes et al., 2001, 2000; De Luca et al., 2005), visual (Cordes et al., 2001, 2000; Lowe et al., 1998; Nir et al., 2006), and auditory (Cordes et al., 2001, 2000) systems. In addition, several studies have demonstrated functional connections within the high-order functional circuits such as the hippocampal-parietal memory network (Vincent et al., 2006) and the default mode network (DMN) during the developmental stage (e.g. Fair et al., 2008) as well as in adults (e.g. Fox et al., 2006,

\footnotetext{
* Corresponding author. Department of Diagnostic Radiology, Yale School of Medicine, The Anlyan Center, 300 Cedar Street, TAC-N134, P.O. Box 208042, New Haven, CT 06520-8042, USA. Fax: +1 2037856643.

E-mail address: roberto.martuzzi@yale.edu (R. Martuzzi).
}

2005; Greicius et al., 2003). Furthermore, recent studies have shown that the strength of the connectivity between specific cortical regions is related to task performance in both working memory (Hampson et al., 2006a) as well as in reading (Hampson et al., 2006b). Despite this widespread use of fc-fMRI to investigate the connections across brain regions, the origin of these phase-locked BOLD low-frequency oscillations remains unclear. In particular, the question as to whether fc-fMRI reflects a specific intrinsic (i.e. unrelated to consciousness) property of brain organization or is more related to the conscious state remains unanswered.

The hypothesis that fc-fMRI is a characteristic of brain organization that goes beyond consciousness is supported by results from nonhuman primates showing that connections within systems such as the occulo-motor, visual, and motor/somatosensory and even within the DMN (or its equivalent in monkeys) remain preserved even at deep levels of anesthesia (Vincent et al., 2007). This observation is also supported by results showing that fc-fMRI patterns reflect anatomical connections, as shown both with staining techniques (Vincent et al., 2007) and with diffusion tensor imaging (DTI; Greicius et al., 2009).

The preceding hypothesis has been challenged by other studies showing that fc-fMRI is modulated by anesthesia or sedation, though the results are often conflicting. Some studies have shown a decrease in fcfMRI under anesthesia (e.g. Lu et al., 2007; Peltier et al., 2007), while others observed an increase in functional connectivity (e.g. Greicius et al., 2008; Kiviniemi et al., 2000, 2005). These results are however difficult to compare because of the differences in dosage, type of anesthetic agents used and brain networks investigated. In addition, 
Table 1

Physiologic measures.

\begin{tabular}{lccll}
\hline & Pre-anesthesia & Anesthesia & $t$-Test & \\
\hline Heat rate (bpm) & $53 \pm 8.0$ & $52 \pm 6.1$ & $t_{(13)}=0.611$ & $p=0.552$ \\
Respiratory rate $(\mathrm{cpm})$ & $14 \pm 2.9$ & $16 \pm 1.7$ & $t_{(13)}=0.327$ & $p=0.136$ \\
$\mathrm{SpO}_{2}(\%)$ & $99 \pm 0.4$ & $99 \pm 0.7$ & $t_{(13)}=-0.444$ & $p=0.664$ \\
$\begin{array}{l}\text { Systolic blood pressure } \\
(\mathrm{mmHg})\end{array}$ & $114 \pm 9.2$ & $109 \pm 7.0$ & $t_{(13)}=3.877$ & $p=0.002$ \\
$\begin{array}{l}\text { Diastolic blood pressure } \\
(\mathrm{mmHg})\end{array}$ & $68 \pm 5.3$ & $63 \pm 5.2$ & $t_{(13)}=2.667$ & $p=0.019$ \\
$\begin{array}{l}\text { Mean blood pressure } \\
(\mathrm{mmHg})\end{array}$ & $83 \pm 6.2$ & $78 \pm 5.2$ & $t_{(13)}=3.145$ & $p=0.008$ \\
EtCO $_{2}(\mathrm{mmHg})$ & $36 \pm 3.2$ & $35 \pm 3.4$ & $t_{(13)}=0.748$ & $p=0.468$ \\
\hline
\end{tabular}

animal studies typically compared fc-fMRI maps between two different levels of anesthesia (Lu et al., 2007), whereas most other studies in humans have compared the results obtained under anesthesia with those obtained in the non-anesthetized condition either in the same group of subjects (Greicius et al., 2008; Kiviniemi et al., 2005; Peltier et al., 2005), or in a separate control group (Kiviniemi et al., 2000).

In the recent years, there has been a growing interest in the analysis of fMRI under anesthesia in humans, but the results are controversial. Some studies have shown no task-related BOLD response in the anesthetized condition (e.g. Antognini et al., 1997; Heinke et al., 2004), while others observed changes in the spatial extent of the response but not in the amplitude of the BOLD response (Marcar et al., 2004). Finally, other studies showed a dose- and regiondependent reduction of the BOLD response under anesthesia (e.g. Kerssens et al., 2005; Plourde et al., 2006). Similarly, fc-fMRI studies under anesthesia showed varying results reporting either increased in functional connectivity under anesthesia (e.g. Greicius et al., 2008; Kiviniemi et al., 2000, 2005), or a decrease in functional connectivity (e.g. Peltier et al., 2007). The explanation for the variation in the results can be found in the different doses and anesthetics agents used in these studies and in the different brain networks investigated.

To better understand whether fc-fMRI reflects a specific intrinsic property (i.e. unrelated to consciousness) of the brain, in the present study we investigated the effects of light anesthesia on functional connectivity between specific cortical regions. Anesthesia alters consciousness level (Alkire et al., 2008), and therefore if fc-fMRI reflects intrinsic properties of the brain, connectivity patterns should be unaffected by the administration of anesthesia. Based on this hypothesis, changes in the strength of connectivity, would suggest that connectivity patterns are influenced by or reflect a consciousnessrelated processes. This hypothesis was tested by comparing fc-fMRI maps in the awake and lightly-anesthetized conditions (sevoflurane end-tidal concentration $1 \%$, equivalent to $0.5 \mathrm{MAC}$, minimum alveolar concentration) across different brain networks, with particular focus on low-level sensory areas (seeding the analysis in the primary somatosensory, visual, and auditory cortices), thalamus, memory (seeding in the hippocampus), and pain (seeding in the insula) circuits, and the default mode network.

\section{Materials and methods}

Subjects and experimental procedures

14 healthy subjects ( 7 male; 11 right and 3 left handed) participated in the study. Subjects' age ranged 22-34 years (mean

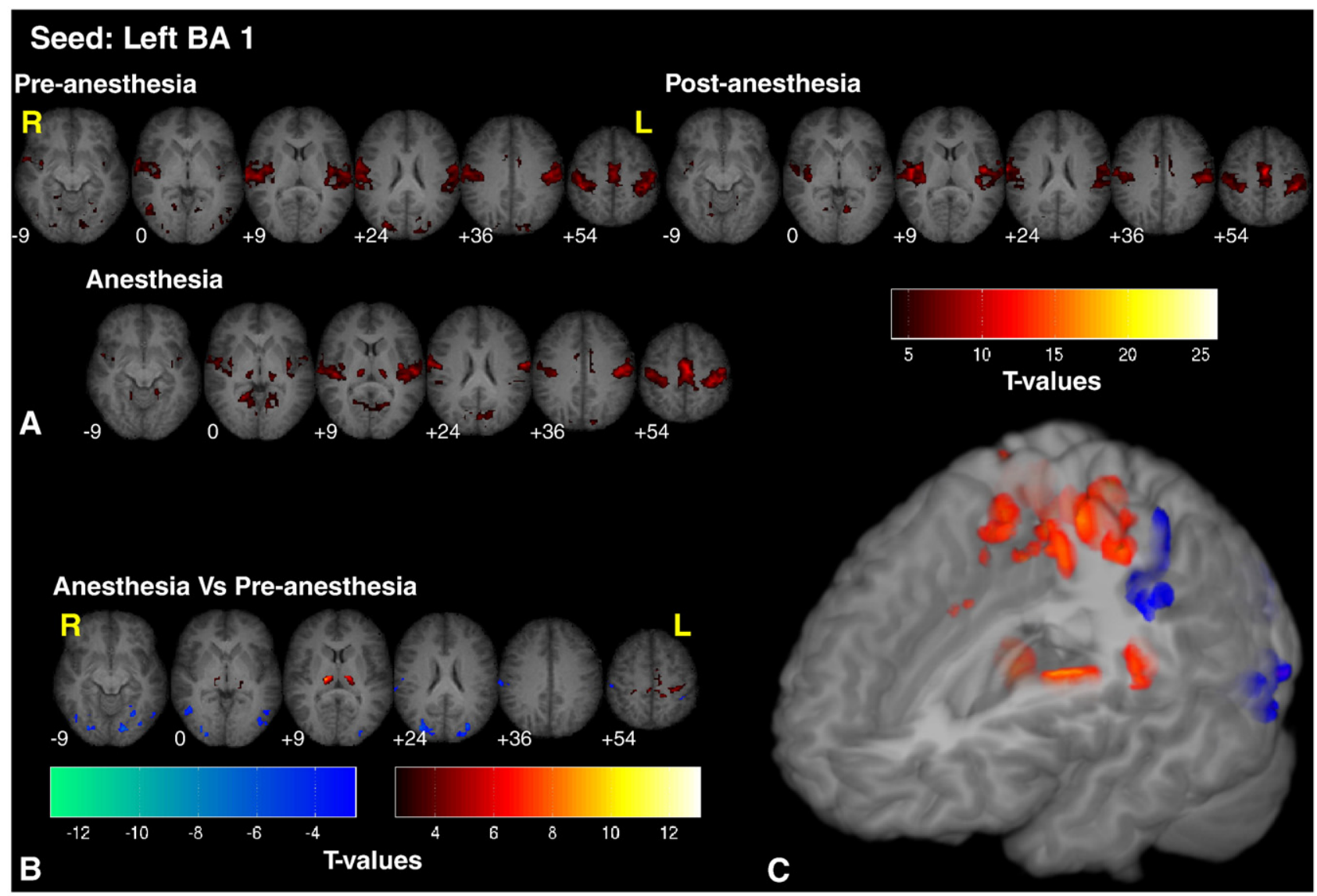

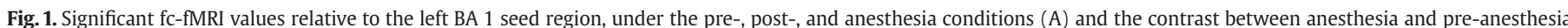

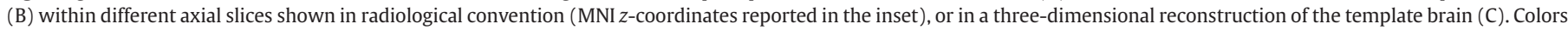

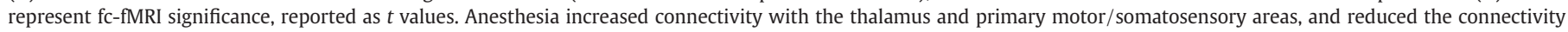
with extrastriate visual areas. 


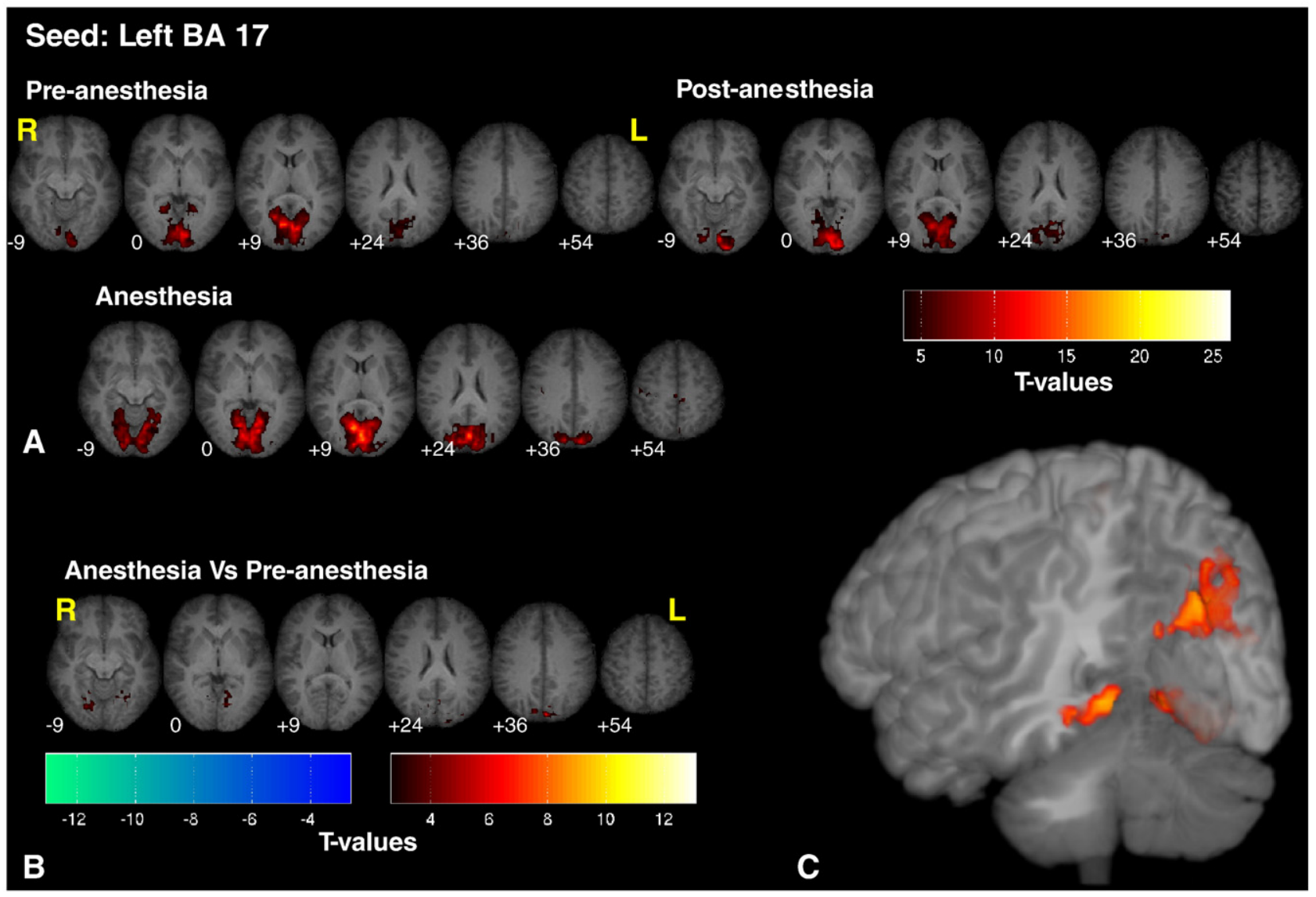

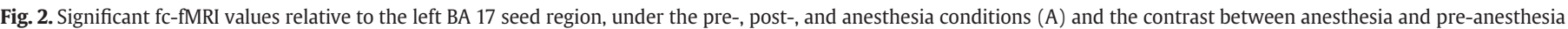

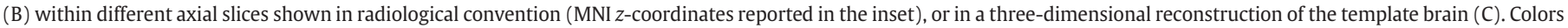
represent fc-fMRI significance, reported as $t$ values. High-order visual areas showed an increased connectivity with BA 17 under anesthesia.

age \pm SD $26.1 \pm 3$ years). All subjects gave written informed consent and the study protocol was approved by the Human Investigation Committee of the Yale School of Medicine (New Haven, CT).

The study was conducted in healthy ASA I (American Society of Anesthesiologists - physical status class I) in the age group of 22 to 34 years. Subjects were interviewed and basic pre-anesthesia screening was carried out prior to the study, to ensure that they fulfilled the inclusion and exclusion criteria. Subjects on psychoactive drugs or any centrally acting medication, history of epilepsy or renal disease, and presence of a potentially difficult airway were part of the exclusion criteria. As a precaution against pulmonary aspiration of gastric contents (causing difficulty in breathing), and in agreement with ASA guidelines (ASA Task Force, 1999), all subjects fasted for $8 \mathrm{~h}$ before the study and did not intake clear liquids for $2 \mathrm{~h}$ prior the experiment. Before the beginning of the acquisitions, an intravenous line was started with a 22-gauge cannula for maintenance infusion (lactated ringer was infused at $100 \mathrm{cc} / \mathrm{h}$ ) and subjects were connected to MRcompatible ASA monitors (EKG, non invasive blood pressure, pulseoximeter and end-tidal carbon dioxide). Additionally, systolic and diastolic blood pressures (BPs and BPd, respectively) were used to compute the mean blood pressure, defined as (BPs + 2BPd)/3. Sevoflurane was administered through a facemask held in place with head straps and connected to a semi-closed circle absorber circuit.

During the entire study, subjects were asked to lie in the scanner with the eyes closed, and to refrain from performing any goal-oriented mental activity. The acquisition protocol comprised of three experimental conditions. In the first condition (pre-anesthesia), pure oxygen was administrated to the subjects, in the second condition (anesthesia) subjects received a mixture of $\mathrm{O}_{2}$ and sevoflurane (end-tidal concen- tration $1 \%$, equivalent to $0.5 \mathrm{MAC}$, minimum alveolar concentration), and in the third condition (post-anesthesia) they received pure oxygen again. Conditions were separated by 10 minute transition periods to allow for end-tidal sevoflurane concentration to reach a steady state and to allow for anesthetic washout (respectively).

At the end of the experiment subjects were monitored in a recovery area and they were discharged home when they were awake and alert, able to dress up and ambulate without help. At this point monitors were disconnected and the intravenous cannula was removed. Subjects were advised not to drive for the next $24 \mathrm{~h}$.

\section{MR data acquisition}

Imaging was performed using a $3 \mathrm{~T}$ Siemens (Erlangen, Germany) Trio MR system with a circularly polarized head coil. After a first localizing scan, 33 axial slices (slice thickness $4 \mathrm{~mm}$, no gap, FoV $=256 \mathrm{~mm}$, matrix size $64 \times 64)$ parallel to the AC-PC line were acquired using a T1-weighted sequence $(\mathrm{TR}=300 \mathrm{~ms}, \mathrm{TE}=2.43 \mathrm{~ms}$, $\mathrm{FoV}=256 \mathrm{~mm}$, matrix size $256 \times 256$, flip angle $\left.60^{\circ}\right)$. Functional imaging volumes were collected in the same slice position as the preceding T1-weighted data. During each of the three experimental conditions (i.e. pre-anesthesia, anesthesia, and post-anesthesia), three functional runs were acquired using a $\mathrm{T} 2 *$-sensitive gradientrecalled, single-shot echo-planar imaging pulse sequence (TR $=2 \mathrm{~s}$, $\mathrm{TE}=31 \mathrm{~ms}, \mathrm{FoV}=256 \mathrm{~mm}$, flip angle $90^{\circ}$, matrix size $\left.64 \times 64\right)$. Each volume consisted of 33 slices parallel to the bicommissural plane (slice thickness $4 \mathrm{~mm}$, no gap), and each functional run was comprised of 210 volumes. 


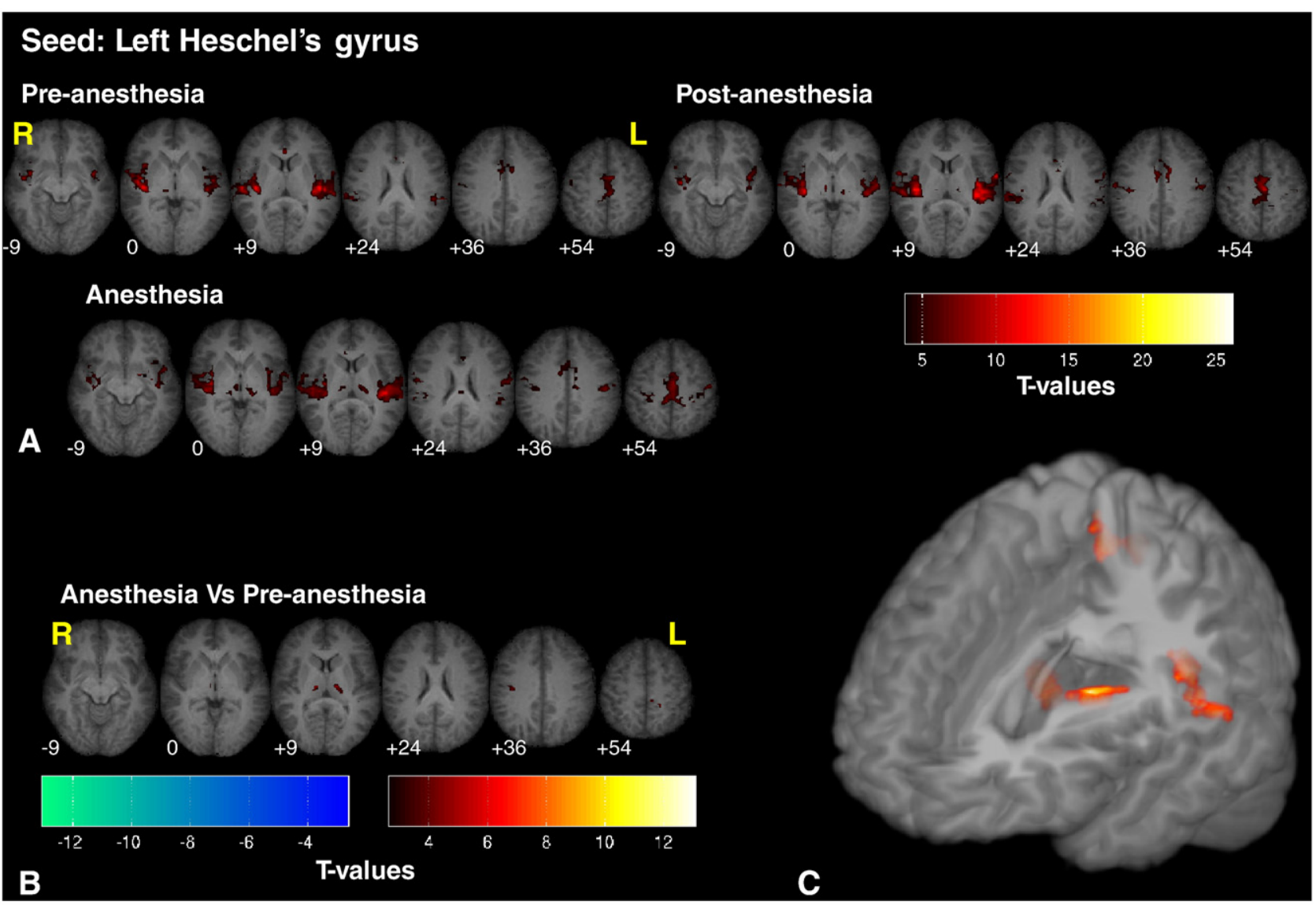

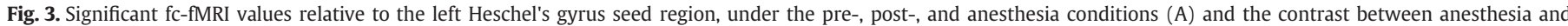

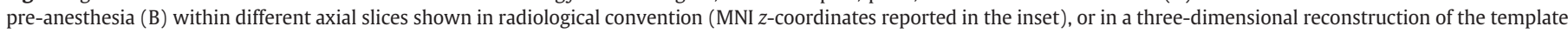

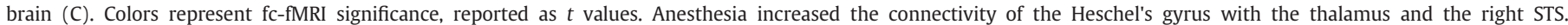

During the washout period, anatomical images were acquired using a T1-weighted sagittal gradient-echo (MPRAGE) sequence (176 contiguous sagittal slices, slice thickness $1 \mathrm{~mm}$, matrix size $256 \times 256$, $\mathrm{FoV}=256 \mathrm{~mm} \mathrm{TR}=2530 \mathrm{~ms}, \mathrm{TE}=3.34 \mathrm{~ms}$, flip angle $=7^{\circ}$ ).

\section{Data analyses}

After discarding the first 10 volumes of each run (to allow for the magnetization to approach steady state), data were temporally and spatially realigned and corrected to remove slice means and drift. Finally, signal at each voxel was low-pass filtered at a cut-off frequency of $0.08 \mathrm{~Hz}$ with a 4th degree elliptical filter and the 6 estimated motion parameters were regressed from the data (see e.g. Laufs et al., 2007), as were the mean signals of white matter and CSF. While cardiac and respiratory rates were continuously monitored, only half of the subjects had artifact free recordings of these physiologic parameters throughout the study and therefore this data was not used to decorrelate these noise components from the fMRI data. Because of the limited anesthesia induced changes in cardiac and respiratory rates, these noise components are not expected to impact the results. A more thorough discussion on this issue and an analysis of a subset of data where these factors are removed are included as Supplementary text. For each of the three conditions, connectivity maps were computed using primary auditory, primary visual and primary somatosensory areas, thalamus, insula, hippocampus bilaterally, and the posterior parietal cortex (PCC) as the seed regions. These fc-fMRI maps were computed in the single-subject space and then transformed into the reference (i.e. MNI) space using a non-linear registration (see below for the details of the normalization proce- dure). Seed regions were anatomically identified on a MNI-T1 template. All the seed regions, with the exclusion of the Heschel's gyrus and the PCC, were selected from the Brodmann Area atlas embedded in Biolmage Suite (www.bioimagesiuite.org). Heschel's gyrus was defined as a subregion of BA 41 (defined according to the BioImage Suite atlas) including only that gyrus. PCC was defined as a sphere of $10 \mathrm{~mm}$-radius and centered in the coordinates ([ $-5-49$ 40] as defined in the Talairach coordinates) reported in the metaanalysis by Shulman et al. (1997). In the fc-fMRI analysis, seed regions were transformed into the single-subject space by applying the inverse of the transformation from the single subject to the reference (i.e. MNI) space (see below). Correlation results were transformed into Gaussian values by applying a Fischer transform (Hays, 1981). Single-subject results were smoothed using a Gaussian kernel (FWHM $=6 \mathrm{~mm}$ ) and normalized to the MNI standard template, using the intensity-only component of the method reported in Papademetris et al. (2004), as implemented within Biolmage Suite software (www.bioimagesuite.org). Spatial normalization includes the computation of three transformations. First, functional EPI images were linearly coregistered to the co-localized T1-2D anatomical image. This individual 2D anatomical image was then linearly registered to the individual MPRAGE (3D anatomical image). Finally, a non-linear registration was applied to transform the individual 3D anatomical volume into the MNI reference space.

Group analyses were carried out as a second level of statistic. For each seed region and for each voxel, a one-sample $t$-test was used to identify statistically significant positive correlation values $(p<0.001$ 20 -voxel cluster threshold). Differences between conditions were tested using a paired $t$-test. These contrasts were computed only in 


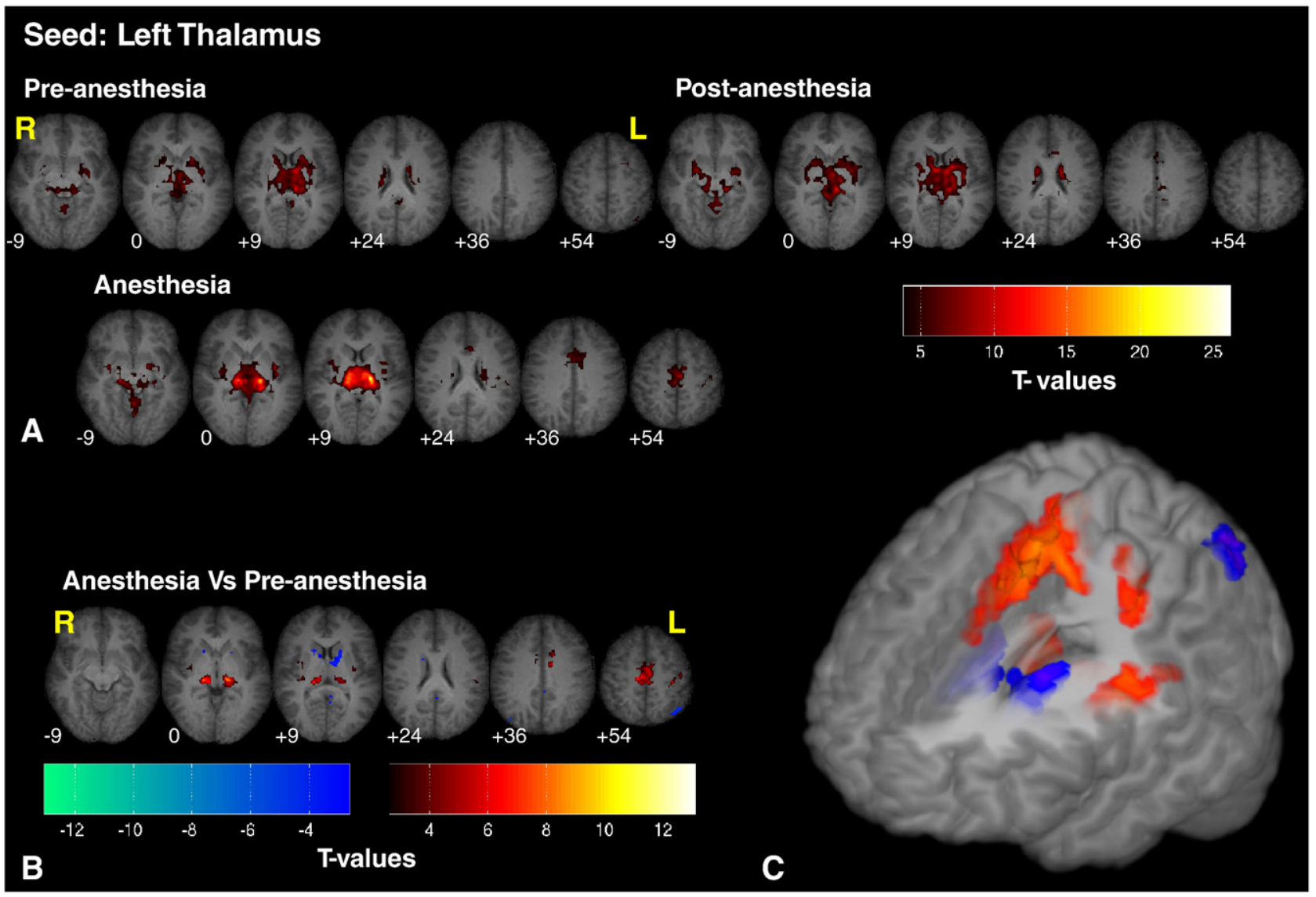

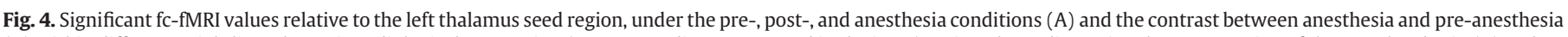

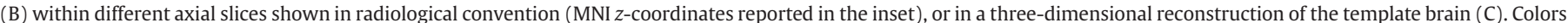

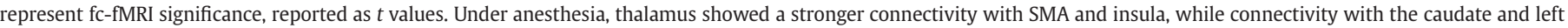
IPL was decreased.

locations showing reliable positive correlations $(p<0.001)$ with the seed region in either condition. Because correction for multiple comparisons was already accounted for in the identification of the positively correlated regions (i.e. the locations where contrasts between conditions were computed), similar to the approach of Beauchamp (2005) we identified significant differences between conditions using a more liberal threshold $(p<0.01,20$-voxel cluster threshold). Anatomical regions were identified from the fc-fMRI maps by using the Talairach Daemon Atlas (Lancaster et al., 2000), after transforming MNI coordinates into Talairach coordinates corrected using a non-linear transformation (Lacadie et al., 2008).

Head movement parameters estimated by the realignment algorithm were used to test whether under anesthesia subjects exhibited a different head movement. For each functional run, the variance of the displacement (translation) with respect to the first volume of the run was first computed. The mean variances across the three preanesthesia and the three anesthesia runs were then calculated. A non-parametric sign test was applied to assess whether these two sets of variances came from populations with equal median.

\section{Results}

Though there were two non-anesthetized imaging cycles (preand post-anesthesia) only the comparison between the preanesthesia and anesthesia conditions is presented. The purpose of introducing a pre- and post-anesthesia imaging was to eliminate the possibility that the alterations in connectivity observed with anesthesia are simply due to order effects. Contrasts between preand post-anesthesia conditions revealed few sparse clusters show- ing significant differences ( $p<0.01,20$-voxel cluster threshold) between these two conditions (see Supplementary Table 1 for the complete list of clusters), indicating the within-session repeatability of our fc-fMRI patterns. However, the second post-anesthesia condition was confounded by subject movement and discomfort as the anesthesia state was reversed and so the results were noisier and thus not included.

To examine the possibility that differences in fc-fMRI results between the pre- and anesthetized conditions reflected changes due to the movement of the head in the subjects, head displacement parameters (in comparison to the first volume acquired for each run), as estimated by the motion correction algorithm, were compared under the pre- and anesthetized runs. This analysis did not reveal any significant head motion difference between the pre- and anesthesia runs (sign test, $p>0.79$ ).

\section{Physiological parameters}

During the MR session physiological parameters, including heart and respiratory rates, blood pressure, end-tidal $\mathrm{CO}_{2}$, and $\mathrm{O}_{2}$ partial pressure $\left(\mathrm{SpO}_{2}\right)$, were constantly monitored and mean physiological values are summarized in Table 1. Comparison of these parameters between the pre-anesthesia and anesthesia states revealed a statistically significant change only in systolic (decreasing from $114 \pm$ $9.2 \mathrm{mmHg}$ to $109 \pm 7.0 \mathrm{mmHg}, p=0.002$ ), diastolic (decreased from $68 \pm 5.3 \mathrm{mmHg}$ to $63 \pm 5.2 \mathrm{mmHg}, p=0.019$ ) and mean blood pressure (decreased from $83 \pm 6.2 \mathrm{mmHg}$ to $78 \pm 5.2 \mathrm{mmHg}, p=0.008$ ) moving from the pre-anesthetic to anesthetic condition. However this change in systolic and diastolic pressure was well within the autoregulatory 


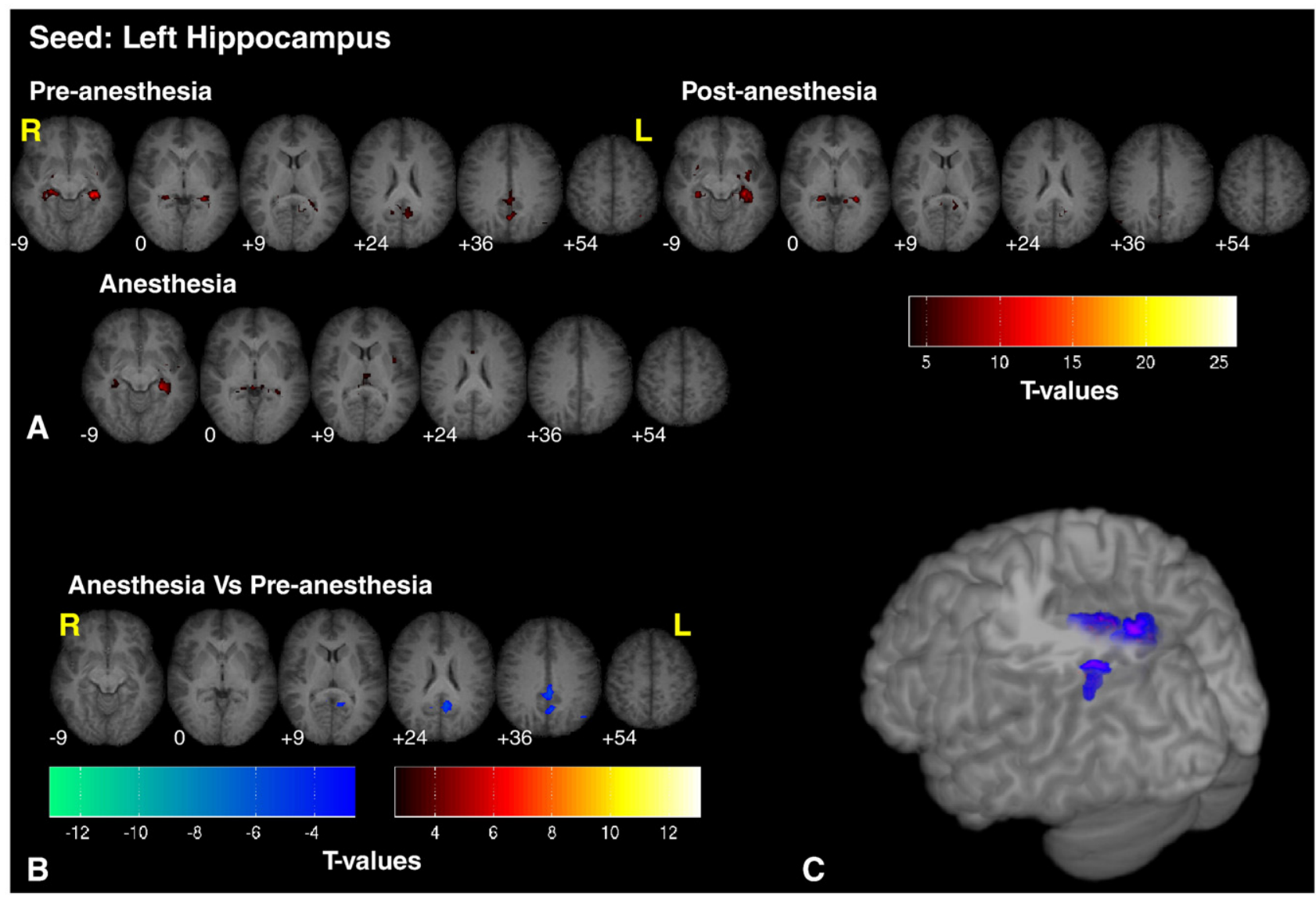

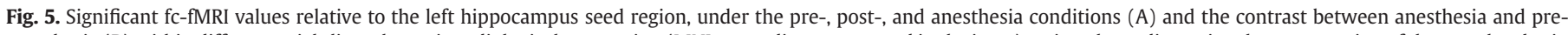

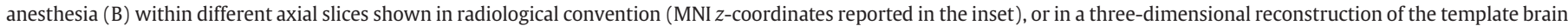
(C). Colors represent fc-fMRI significance, reported as $t$ values. Connectivity between hippocampus and PCC and IPL was reduced by anesthesia.

range (Drummond, 1997) and was not expected to induce cerebral hemodynamic changes. Heart rate, respiratory rates, $\mathrm{SpO}_{2}$, and end-tidal $\mathrm{CO}_{2}$, did not show significant change $(p>0.1)$ with $0.5 \mathrm{MAC}$ sevoflurane anesthesia.

\section{Connectivity maps}

Connectivity maps were computed for the pre- and anesthesia states using primary somatosensory, visual, auditory cortices, thalamus, hippocampus, insula, and PCC as seed regions. To investigate functional alterations associated with 0.5 MAC sevoflurane anesthesia the following seed regions were selected: thalamus a region that modulates consciousness; the hippocampus which is linked to memory; the insula, a region consistently activated in acute pain; and the PCC which is part of the DMN, and may be involved in self referential processing (e.g. Buckner et al., 2008; Johnson et al., 2006). Visual and auditory cortices were chosen based on our previous data indicating that these regions are preferentially affected under low dose sevoflurane anesthesia (Qiu et al., 2008b).

Functional connectivity results $(p<0.001 ; 20$-voxel cluster threshold) were highly consistent across homologous seed regions within the two hemispheres. Therefore, Figs. 1-7 as well as Tables 2 and 3 report the results relative only to the seed regions in the left hemisphere. All the areas showing differences in connectivity between the two anesthetic levels are also reported in Tables 2 and 3. Results relative to the right seed regions are available as Supplemental data.

In the following section the results revealing the networks connected to the individual seed regions (significant at $p<0.001$; 20-voxel cluster threshold) and the changes in connectivity between the pre- and anesthetized conditions are described (significant at $p<0.01 ; 20$-voxel cluster threshold; analysis limited to the regions showing significant connectivity in either condition).

1) Functional connectivity with the Brodmann Area (BA) 1 (i.e. primary somatosensory cortex) was significant across the entire bilateral somatosensory and motor network in both the preanesthesia and anesthesia conditions (see Fig. 1 and Supplementary Fig. 1 for the right BA 1 seed). The areas that were part of this network included, primary somatosensory (S1) and motor areas (M1) bilaterally, supplementary motor area (SMA), pre-SMA, bilateral thalamus, secondary somatosensory area (SII), and the intraparietal sulcus (IPS). In addition, connections with other sensory cortices, such as the auditory and the visual areas (mostly with the extrastriate cortices) were also significant. Contrasting connectivity maps between the pre- and anesthetic conditions, we observed that under anesthesia left BA 1 showed increased connectivity with the thalamus as well as within limited regions within the primary motor/somatosensory areas. Conversely, reduced connectivity was observed between area BA 1 and the extrastriate visual areas, such as the lingual gyrus and the superior occipital gyrus, bilaterally.

2) Seeding in BA 17 (i.e. primary visual area) revealed significant connections only within the visual cortex (see Fig. 2 and Supplementary Fig. 2 for the right BA 17 seed). Bilateral highorder visual areas within the cuneus (BA 19) and the lingual gyrus showed stronger connectivity under anesthesia than in the preanesthesia condition. No regions showed decreases in functional 


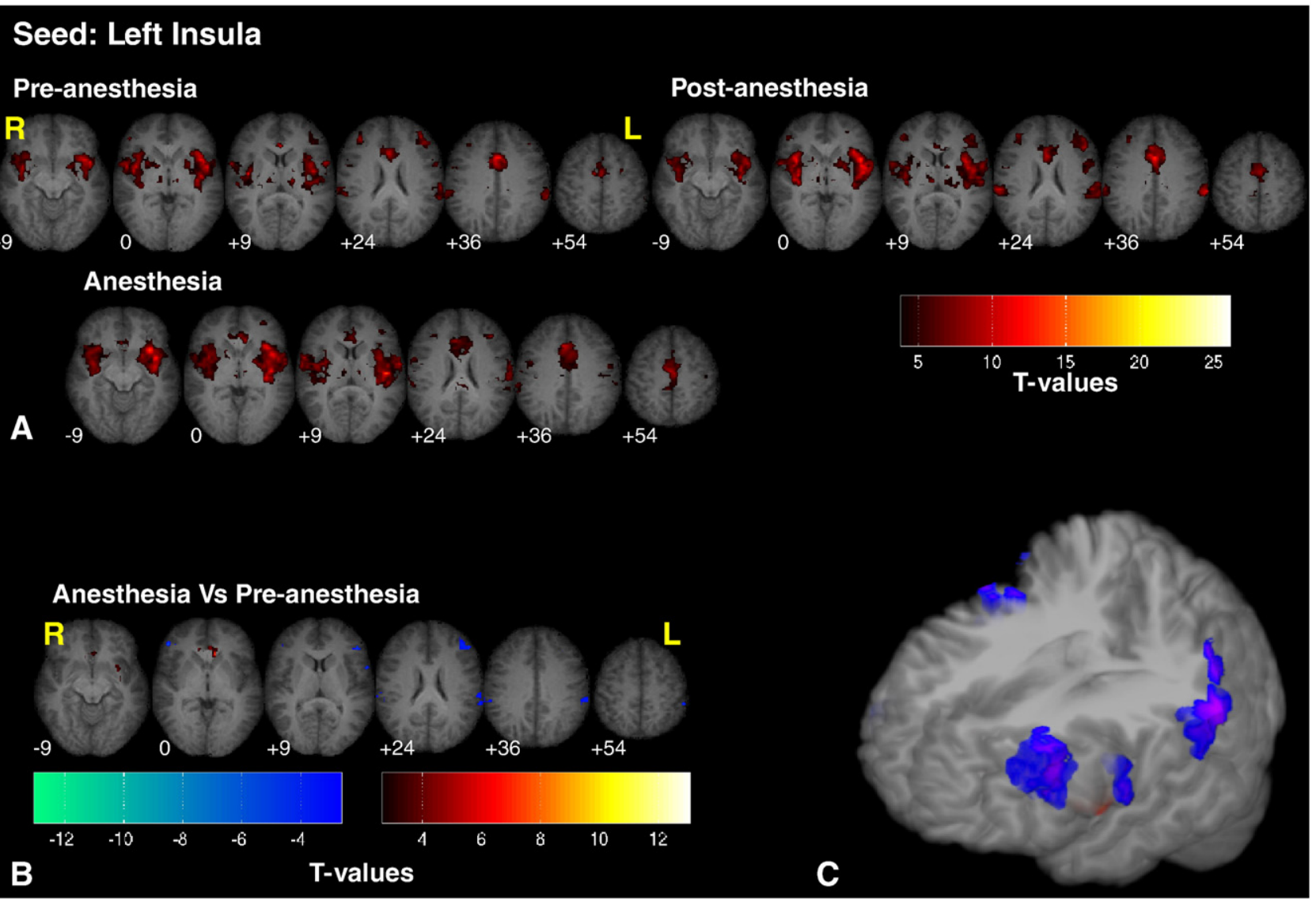

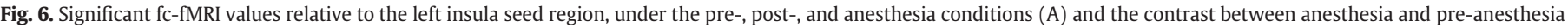

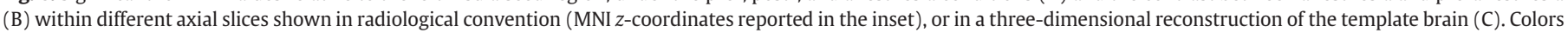
represent fc-fMRI significance, reported as $t$ values. Under anesthesia, connectivity with bilateral SII and with left middle frontal gyrus was reduced.

connectivity under anesthesia when using the visual cortex as the seed.

3) Seeding in Heschel's gyrus (i.e. primary auditory cortex) revealed connectivity with the entire auditory cortex bilaterally, the thalamus, and the anterior cingulate cortex (ACC), as shown in Fig. 3 (see Supplementary Fig. 3 for the right Heschel's gyrus seed). We observed increased connectivity under anesthesia in the thalamus bilaterally, in the right STS, and in part of the motor areas. Under anesthesia no regions showed decreases in functional connectivity with Heschel's gyrus.

4) Seeding in the thalamus revealed a network including all the deep structures of the brain, such as the putamen, the caudate nucleus bilaterally (basal ganglia), and the brainstem (see Fig. 4 and Supplementary Fig. 4 for the right thalamus seed). Anesthesia highlighted the connectivity between the thalamus and the SMA. In addition, anesthesia also increased connectivity between the thalamus and insula, while reducing the connectivity between the thalamus and the caudate and the left inferior parietal lobule (IPL).

5) Seeding in the hippocampus, revealed significant connectivity with the contralateral hippocampus, posterior cingulate cortex (PCC) adjacent to the precuneus, and the left inferior parietal lobule (IPL), as shown in Fig. 5 (see Supplementary Fig. 5 for the right hippocampus seed). Connectivity with the PCC and bilateral IPL showed significant correlations only in the pre-anesthetized conditions. Under anesthesia no regions showed increased connectivity with the hippocampus.

6) Connectivity maps to the insula seed region reveal significant connections with the ACC, SII and the middle frontal gyrus bilaterally (see Fig. 6 and Supplementary Fig. 6 for the right insula seed). Under anesthesia connectivity with the bilateral SII and with the left middle frontal gyrus was reduced, while connectivity with the ACC and the left putamen was increased.

7) Seeding with the PCC revealed significant connectivity with the anterior cingulate cortex (ACC) and with the IPL bilaterally (see Fig. 7). Anesthesia increased the connectivity between PCC and the superior temporal gyrus (STG) and reduced connectivity with areas adjacent to the seed region.

\section{Discussion}

The main aim of this study was to investigate the effects of changes in brain baseline activity on fc-fMRI. This aim was pursued by analyzing the changes in fc-fMRI maps induced by $1 \%$ (equivalent to $0.5 \mathrm{MAC}$ ) sevoflurane anesthesia.

We observed high repeatability of within-session fc-fMRI patterns, also in agreement with recent results by Shehzad et al. (in press). This finding eliminates the possibility that the observed differences in fcfMRI between pre- and anesthesia conditions were due to an order effect and/or changes in the baseline associated with starting another sequence. We also consider highly unlikely - while we cannot exclude completely this possibility - that the results shown are driven by anesthesia-related changes in the hemodynamics and not in the neuronal response for two main reasons. First, fc-fMRI is insensitive to signal amplitude. Indeed, the effect of a reduced range of BOLD signal fluctuations might change the correlations because it reduces the signal-to-noise ratio, and if this were the case a global decrease in connectivity under anesthesia should be observed. The concomitant presence of both increased and decreased connectivity, found in the 


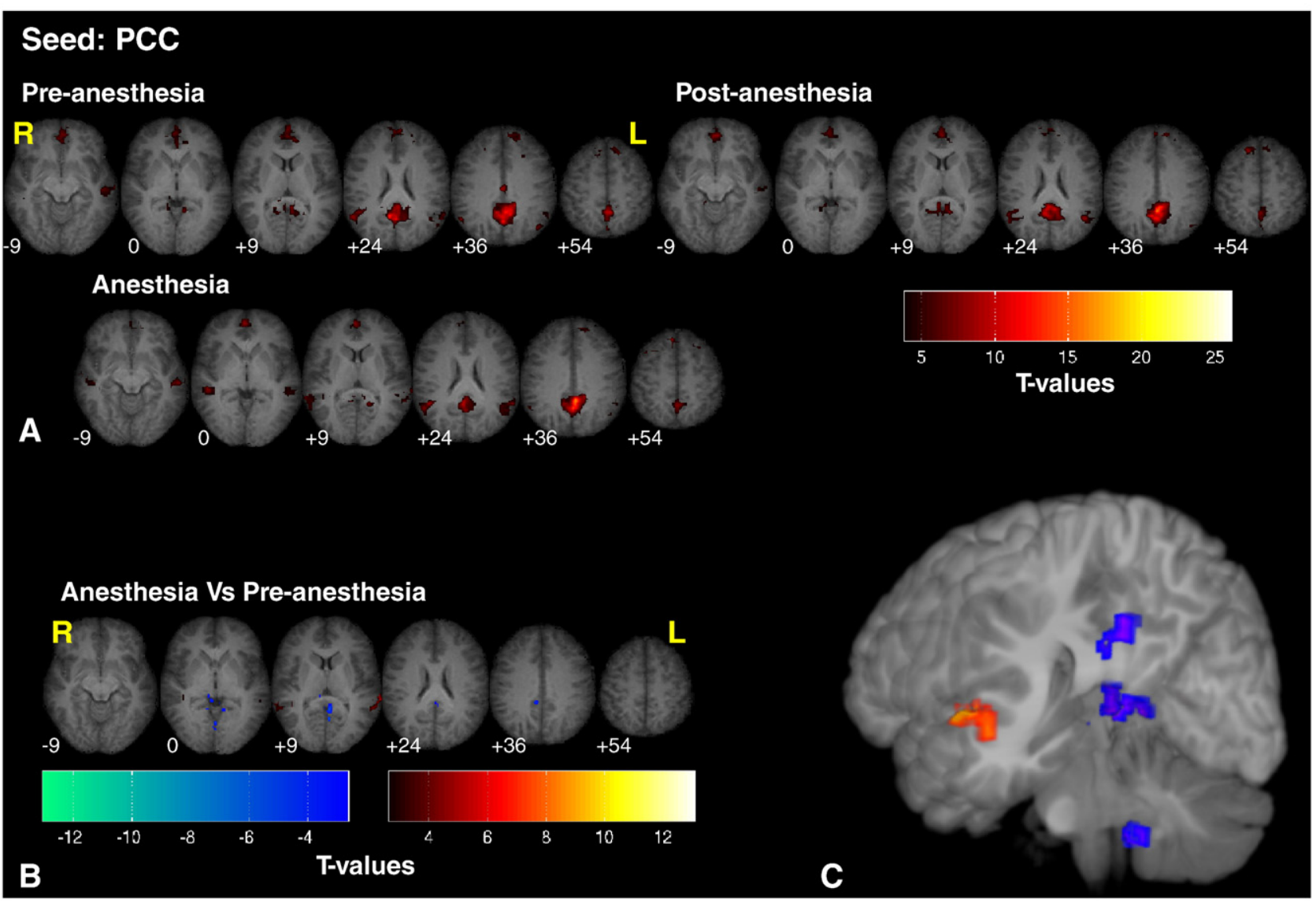

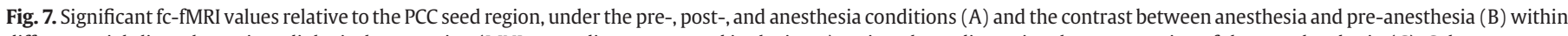

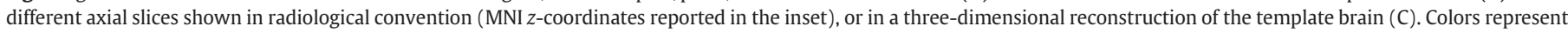
fc-fMRI significance, reported as $t$ values. Anesthesia increased the connectivity between PCC and STG and reduced connectivity with areas adjacent to the seed region.

present study, instead suggests a neuronal origin for these changes. Second, if the changes in correlations simply reflected a reduced range of the BOLD oscillations, we would expect correlations to decrease throughout the brain, irrespectively of the seed regions used. Instead, we observed changes in BOLD correlations only with some specific seed regions, and these changes were highly localized within specific brain circuits.

Because of technical limitations, the results presented in this paper were obtained without correcting the data for cardio-respiratory confounds. To evaluate the impact cardio-respiratory artifacts, physiologic noise correction was performed using the RETROICOR algorithm (Glover et al., 2000) on a subset of 7 subjects (results shown in Supplementary Figs. 7 and 8). Although in this analysis we used a more liberal threshold than in the analysis of all the 14 subjects, the results replicated the main findings of this study and illustrate the minimal impact that this correction has on the results shown. In addition, comparing the results obtained with and without applying the RETROICOR algorithm, it is difficult to dissociate the contribution of variations due to the noise correction approach itself and to that due to the reduced number of subjects.

Functional connectivity analysis revealed significant correlations within the sensory system (e.g. see Biswal et al., 1995; Cordes et al., 2001, 2000; De Luca et al., 2005; Lowe et al., 1998; Nir et al., 2006 for similar results involving motor/somatosensory, auditory, and visual cortices), as well as significant correlations between the primary and secondary somatosensory areas, visual and auditory cortices. These results were replicated when the primary auditory cortex was used as seed regions. Visuo-somatosensory connections have been demonstrated both with tracing techniques in primates (e.g. Cappe and
Barone, 2005; Négyessy et al., 2006) and with fc-fMRI in humans (Yu et al., 2008). Similarly, auditory-somatosensory connections have been identified by tracing studies (Smiley et al., 2007) as well as by electrophysiology (e.g. Fu et al., 2003; Lakatos et al., 2007; Schroeder et al., 2001). Our results did not reveal significant connections between auditory and visual cortices, as shown by Eckert et al. (2008). Several studies have shown that primary auditory and visual areas play a role in integrating multisensory inputs (e.g. Kayser et al., 2005, 2008; Martuzzi et al., 2007) and the present results add converging evidence of communications between sensory-specific brain areas. Functional connectivity however cannot reveal whether these communications occur directly between these areas or if they are mediated by other multisensory regions.

Functional connectivity maps obtained with and without administration of an anesthetic drug revealed consistent connectivity patterns, notwithstanding some significant differences, associated mostly with higher-order cognitive processing regions. The results suggest that functional brain organization is preserved under anesthesia and are in agreement previous studies showing that fcfMRI patterns remain essentially unchanged even under deep anesthesia in monkeys (Vincent et al., 2007) as well as in humans during sleep, (Horovitz et al., 2008), sedation (Kiviniemi et al., 2005), and in comatose patients (Boly et al., 2008, in press). In addition, anatomical studies conducted with staining techniques (Vincent et al., 2007) and DTI (Greicius et al., 2009) confirmed anatomical connectivity between regions identified by fc-fMRI analysis.

While most networks are preserved under low levels of anesthesia, significant changes were observed between the pre- and anesthetized conditions for some seed regions. The most significant differences 
Table 2

List of the regions showing differences in fc-fMRI between the pre- and anesthesia conditions with low-level sensory areas of the left hemisphere.

\begin{tabular}{|c|c|c|c|c|c|c|c|c|c|c|}
\hline \multicolumn{3}{|c|}{ MNI coord (mm) } & \multicolumn{3}{|c|}{ Talairach coord (mm) } & \multirow[t]{2}{*}{$t$ Values } & \multirow{2}{*}{$\begin{array}{l}\text { Cluster } \\
\text { size }\end{array}$} & \multirow{2}{*}{\multicolumn{2}{|c|}{ Brain region }} & \multirow{2}{*}{$\begin{array}{l}\text { Brodmann } \\
\text { Area }\end{array}$} \\
\hline$x$ & $y$ & $z$ & $x$ & $y$ & $z$ & & & & & \\
\hline \multicolumn{11}{|l|}{ Left BA1 } \\
\hline \multicolumn{11}{|c|}{ Anesthesia > pre-anesthesia } \\
\hline 18 & -21 & 12 & 17 & -21 & 14 & 9.17 & 58 & $\mathrm{R}$ & Thalamus & \\
\hline-24 & -30 & 60 & -24 & -26 & 54 & 7.72 & 423 & $\mathrm{~L}$ & Precentral gyrus & BA4 \\
\hline 18 & -30 & 63 & 19 & -26 & 57 & 7.1 & & $\mathrm{R}$ & Precentral gyrus & BA4 \\
\hline-9 & -15 & 9 & -8 & -16 & 11 & 7.08 & 50 & $\mathrm{~L}$ & Thalamus & \\
\hline-36 & -33 & 21 & -35 & -32 & 21 & 5.1 & 28 & $\mathrm{~L}$ & Insula & BA13 \\
\hline \multicolumn{11}{|c|}{ Pre-anesthesia > anesthesia } \\
\hline 39 & -81 & -3 & 40 & -80 & 2 & 8.68 & 163 & $\mathrm{R}$ & Middle occipital gyrus & BA19 \\
\hline-27 & -78 & -12 & -27 & -77 & -5 & 8.2 & 68 & $\mathrm{~L}$ & Lingual gyrus & BA18 \\
\hline 36 & -81 & 21 & 37 & -78 & 22 & 7.94 & 91 & $\mathrm{R}$ & Middle temporal gyrus & BA19 \\
\hline-15 & -84 & -9 & -15 & -81 & -3 & 7.31 & 21 & $\mathrm{~L}$ & Lingual gyrus & BA18 \\
\hline-27 & -66 & -9 & -26 & -65 & -3 & 7.21 & 44 & $\mathrm{~L}$ & Lingual gyrus & BA19 \\
\hline 63 & -27 & 39 & 62 & -25 & 37 & 6.61 & 100 & $\mathrm{R}$ & Postcentral gyrus & BA2 \\
\hline-27 & -81 & 24 & -27 & -77 & 24 & 6.38 & 80 & $\mathrm{~L}$ & Superior occipital gyrus & BA19 \\
\hline-36 & -45 & 57 & -36 & -42 & 52 & 4.72 & 49 & $\mathrm{~L}$ & Inferior parietal lobule & BA40 \\
\hline-57 & -30 & 42 & -56 & -28 & 39 & 3.39 & 13 & $\mathrm{~L}$ & Postcentral gyrus & BA2 \\
\hline \multicolumn{11}{|c|}{ Left BA17 } \\
\hline \multicolumn{11}{|c|}{ Anesthesia $>$ pre-anesthesia } \\
\hline-3 & -87 & 36 & -3 & -82 & 34 & 6.32 & 280 & $\mathrm{~L}$ & Cuneus & BA19 \\
\hline 12 & -81 & 36 & 12 & -77 & 34 & 4.05 & & $\mathrm{R}$ & Cuneus & BA19 \\
\hline-18 & -60 & -3 & -17 & -59 & 1 & 5.28 & 137 & $\mathrm{~L}$ & Lingual gyrus & BA19 \\
\hline 24 & -75 & -6 & 25 & -73 & 0 & 4.73 & 145 & $\mathrm{R}$ & Lingual gyrus & BA19 \\
\hline-33 & -87 & 21 & -33 & -83 & 22 & 4.54 & 43 & $\mathrm{~L}$ & Superior occipital gyrus & BA19 \\
\hline \multicolumn{11}{|c|}{$\begin{array}{l}\text { Pre-anesthesia > anesthesia } \\
\text { No suprathreshold clusters }\end{array}$} \\
\hline \multicolumn{11}{|c|}{ Left Heschel's gyrus } \\
\hline \multicolumn{11}{|c|}{ Anesthesia $>$ pre-anesthesia } \\
\hline-12 & -15 & 6 & -11 & -16 & 8 & 5.05 & 28 & $\mathrm{~L}$ & Thalamus & \\
\hline-42 & -36 & 15 & -40 & -35 & 16 & 4.9 & 32 & $\mathrm{~L}$ & Superior temporal gyrus & BA41 \\
\hline 12 & -18 & 6 & 11 & -19 & 8 & 4.71 & 34 & $\mathrm{R}$ & Thalamus & \\
\hline 39 & -18 & 33 & 38 & -16 & 32 & 4.62 & 20 & $\mathrm{R}$ & Precentral gyrus & BA6 \\
\hline-18 & -42 & 54 & -18 & -39 & 49 & 4.17 & 20 & $\mathrm{~L}$ & Paracentral lobule & BA5 \\
\hline \multicolumn{11}{|c|}{$\begin{array}{l}\text { Pre-anesthesia > anesthesia } \\
\text { No suprathreshold clusters }\end{array}$} \\
\hline \multicolumn{11}{|c|}{ Left thalamus } \\
\hline \multicolumn{11}{|c|}{ Anesthesia > pre-anesthesia } \\
\hline-15 & -24 & 3 & -14 & -25 & 6 & 10.76 & 120 & $\mathrm{~L}$ & Thalamus & \\
\hline 15 & -24 & 3 & 14 & -24 & 6 & 10.2 & 122 & $\mathrm{R}$ & Thalamus & \\
\hline-42 & -12 & 12 & -40 & -13 & 13 & 7.53 & 73 & $\mathrm{~L}$ & Insula & BA13 \\
\hline 39 & -15 & 12 & 37 & -15 & 14 & 7.48 & 99 & $\mathrm{R}$ & Insula & BA13 \\
\hline 12 & -24 & 54 & 12 & -21 & 49 & 6.84 & 488 & $\mathrm{R}$ & Medial frontal gyrus & BA6 \\
\hline-3 & -12 & 57 & -2 & -8 & 52 & 6.65 & & $\mathrm{~L}$ & Medial frontal gyrus & BA6 \\
\hline-36 & -27 & 51 & -36 & -24 & 47 & 6.32 & 62 & $\mathrm{~L}$ & Precentral gyrus & BA4 \\
\hline \multicolumn{11}{|c|}{ Pre-anesthesia $>$ anesthesia } \\
\hline 42 & -75 & 36 & 43 & -71 & 34 & 7.83 & 21 & $\mathrm{R}$ & Precuneus & BA39 \\
\hline-6 & -45 & 48 & -5 & -42 & 44 & 5.94 & 23 & $\mathrm{~L}$ & Precuneus & BA7 \\
\hline-45 & -60 & 54 & -45 & -56 & 50 & 5.86 & 30 & $\mathrm{~L}$ & Inferior parietal lobule & BA40 \\
\hline-3 & -54 & 9 & -2 & -53 & 11 & 5.06 & 22 & $\mathrm{~L}$ & Posterior cingulate & BA29 \\
\hline-15 & 15 & 6 & -14 & 12 & 7 & 4.88 & 104 & $\mathrm{~L}$ & Caudate & \\
\hline 18 & 15 & 9 & 17 & 13 & 10 & 4.11 & 76 & $\mathrm{R}$ & Caudate & \\
\hline
\end{tabular}

were observed in the connectivity maps linked to the hippocampus and the insula. Connectivity between the hippocampus and the PCC/ precuneus and IPL, bilaterally were present only in the preanesthetized state. These are regions previously shown to be involved in episodic memory retrieval (Meltzer and Constable, 2005; Rekkas and Constable, 2005, 2006; Shannon and Buckner, 2004; Wheeler and Buckner, 2004) among other functions. In the anesthetized condition, connectivity between the insula and the ACC increased, while connectivity between the insula and secondary somatosensory areas decreased, bilaterally. Functional imaging studies with pain activation have revealed consistent activation of insula, ACC and SII in response to painful stimuli across several studies (see Tracey and Mantyh, 2007 for a review). These changes in connectivity involving the pain and memory circuits may reflect the analgesic and amnesic effects of 0.5 MAC sevoflurane anesthesia (Ramani and Wardhan, 2008). Seeding in the thalamus we observed that anesthesia led to reduced connectivity between the thalamus and the PCC, a region that, in conjunction with the mesial parietal cortex and the precuneus, is usually deactivated in the unconscious state (Alkire et al., 2008; Franks, 2008) and a region that is one of the first to recover functionally from coma (Laureys et al., 2006). Therefore, the reduced connectivity between thalamus and PCC may reflect the subjects' loss of consciousness, as at this level of anesthetic all subjects were asleep and did not respond to commands. We also observed an increase in connectivity between the thalamus and motor/somatosensory regions under anesthesia. A possible explanation for such behavior is related to the fact that under anesthesia, increased disinhibition (Fiset et al., 1999; Schlünzen et al., 2004) leads subjects to have a tendency to move, mostly the lower limbs, noting that significant changes $(p>0.79)$ in head motion were not observed between the pre- and anesthetized periods. Increased 
Table 3

List of the regions showing differences in fc-fMRI between the pre- and anesthesia conditions, with higher-order functional areas of the left hemisphere.

\begin{tabular}{|c|c|c|c|c|c|c|c|c|c|c|}
\hline \multicolumn{3}{|c|}{ MNI coord (mm) } & \multicolumn{3}{|c|}{ Talairach coord (mm) } & \multirow[t]{2}{*}{$t$ Values } & \multirow{2}{*}{$\begin{array}{l}\text { Cluster } \\
\text { size }\end{array}$} & \multirow{2}{*}{\multicolumn{2}{|c|}{ Brain region }} & \multirow{2}{*}{$\begin{array}{l}\text { Brodmann } \\
\text { Area }\end{array}$} \\
\hline$x$ & $y$ & $z$ & $x$ & $y$ & $z$ & & & & & \\
\hline \multicolumn{11}{|c|}{ Left Hippocampus } \\
\hline \multicolumn{11}{|c|}{$\begin{array}{l}\text { Anesthesia> pre-anesthesia } \\
\text { No suprathreshold clusters }\end{array}$} \\
\hline \multicolumn{11}{|c|}{ Pre-anesthesia $>$ anesthesia } \\
\hline-3 & -54 & 21 & -2 & -52 & 22 & 7.69 & 253 & $\mathrm{~L}$ & Posterior cingulate & BA23 \\
\hline-45 & -66 & 48 & -45 & -62 & 45 & 5.13 & 28 & $\mathrm{~L}$ & Inferior parietal lobule & BA40 \\
\hline 6 & -51 & 18 & 6 & -49 & 19 & 4.96 & 48 & $\mathrm{R}$ & Posterior cingulate & BA30 \\
\hline \multicolumn{11}{|c|}{ Left Insula } \\
\hline \multicolumn{11}{|c|}{ Anesthesia > pre-anesthesia } \\
\hline-9 & 27 & 0 & -9 & 24 & 1 & 8.02 & 69 & $\mathrm{~L}$ & Caudate & \\
\hline-27 & 15 & -3 & -26 & 11 & 0 & 4.41 & 39 & $\mathrm{~L}$ & Putamen & \\
\hline \multicolumn{11}{|c|}{ Pre-anesthesia $>$ anesthesia } \\
\hline-60 & -39 & 30 & -58 & -37 & 30 & 7.19 & 148 & $\mathrm{~L}$ & Inferior parietal lobule & BA40 \\
\hline 51 & 39 & 0 & 49 & 37 & 3 & 7.06 & 22 & $\mathrm{R}$ & Inferior frontal gyrus & BA46 \\
\hline-42 & 36 & 21 & -41 & 35 & 20 & 6.23 & 128 & $\mathrm{~L}$ & Middle frontal gyrus & BA46 \\
\hline-60 & 9 & 9 & -57 & 6 & 11 & 5.73 & 18 & $\mathrm{~L}$ & Precentral gyrus & BA44 \\
\hline 69 & -27 & 30 & 67 & -25 & 30 & 4.74 & 73 & $\mathrm{R}$ & Inferior parietal lobule & BA40 \\
\hline \multicolumn{11}{|l|}{ PCC } \\
\hline \multicolumn{11}{|c|}{ Anesthesia $>$ pre-anesthesia } \\
\hline-66 & -39 & 9 & -63 & -39 & 12 & 5.18 & 66 & $\mathrm{~L}$ & Superior temporal gyrus & BA22 \\
\hline 42 & -42 & 3 & 41 & -42 & 7 & 4.02 & 34 & $\mathrm{R}$ & Superior temporal gyrus & BA41 \\
\hline 63 & -45 & 6 & 61 & -44 & 10 & 4.09 & 29 & $\mathrm{R}$ & Superior temporal gyrus & BA22 \\
\hline \multicolumn{11}{|c|}{ Pre-anesthesia $>$ anesthesia } \\
\hline-3 & -48 & 12 & -2 & -47 & 14 & 6.59 & 126 & $\mathrm{~L}$ & Posterior cingulate & ВА30 \\
\hline 3 & -57 & -45 & 3 & -59 & -35 & 4.36 & 33 & $\mathrm{R}$ & Cerebellum & \\
\hline-9 & -48 & -39 & -8 & -49 & -30 & 4.04 & & $\mathrm{~L}$ & Cerebellum & \\
\hline
\end{tabular}

motor activity under anesthesia may account for the increased connectivity between the sensory-motor cortex and the thalamus. Another explanation for the increased thalamo-cortical connection rests on the observations that anesthesia reduces thalamic communication, including the afferent sensory input to the thalamus (Alkire et al., 2000, 2005; Fiset et al., 1999) and that, under anesthesia, thalamic spontaneous activity is mainly driven by feedback connections coming from the cortical neurons (Vahle-Hinz et al., 2007). Our results suggest that these feedback connections are not equally attenuated by anesthetics such that an uneven reduction of afferent input to the thalamus highlights the most robust and direct connections of thalamus, such as those with the primary motor and somatosensory cortices. Further investigations are required to clarify whether the increased thalamo-cortical connectivity is related to the anesthesia induced decrease in sensory input to the thalamus or to the disinhibitory effects of anesthesia. Seeding in the primary somatosensory regions, we replicated the finding of increased connectivity between the thalamus and somatosensory cortices under anesthesia. We also observed a decreased connectivity with extrastriate (i.e. non-primary) visual areas. Multisensory connections are mediated and/or modulated by highorder connections and these are among the first regions to be affected under anesthesia (Ramani et al., 2007). This could explain the decrease in connectivity with the extra striate visual areas. Functional connectivity of the primary visual (BA 17) and auditory (Heschel's gyrus) areas appeared to be minimally modified by anesthesia.

In accord with previous findings, seeding in the PCC revealed connection throughout the default mode network (DMN; e.g. Buckner et al., 2008; Shulman et al., 1997), and this functional pattern seems to be minimally altered by sevoflurane at 0.5 MAC. This result is in agreement with previous studies showing that DMN is preserved in anesthetized monkeys (Vincent et al., 2007) and in comatose patients (Boly et al., in press), suggesting that the DMN connectivity is still preserved even in case of loss of consciousness.

Despite the observation that fc-fMRI patterns were mostly preserved under anesthesia, this study also revealed that anesthesia modulates the strength of functional connectivity in a networkspecific manner. Consistent with an earlier study using midazolam sedation (Greicius et al., 2008) we observed decreased connectivity in the high-order association areas (hippocampus and insula). However in the primary sensory cortical areas there was minimal alteration in fc-fMRI under anesthesia, with a trend towards an increase in connectivity. Such an increase in functional connectivity has also been observed under midazolam sedation (Kiviniemi et al., 2000). Other studies using anesthesia have demonstrated a dose-dependent reduction in fc-fMRI, both in animals (Lu et al., 2007; Vincent et al., 2007) as well as in humans (Peltier et al., 2005). In the study by Peltier et al. (2005), they observed a significant reduction in functional connectivity with regions connected to the motor cortex (98\% reduction in connectivity) when $1 \mathrm{MAC}$ sevoflurane anesthesia was administered. We did not observe such a large decrease in connectivity in the present study possibly because of the lower dose used: 0.5 MAC sevoflurane. In animals studies (Lu et al., 2007; Vincent et al., 2007) bilateral fc-fMRI has been observed to be maintained even at higher anesthetic doses.

In addition to the observation that most fc-fMRI patterns remain consistent in the pre- and anesthetized conditions, some anestheticinduced modulations were also observed. The differential responses to fc-fMRI observed here (decreases in connectivity with the anesthesia in some regions, no change in others, and even increases in a few regions) suggest that anesthesia does not affect the brain in a homogeneous manner. Initially anesthesia alters the functional networks involved in higher-order cognitive function, such as memory and pain processing. Subsequently at higher doses the thalamocortical connections (White and Alkire, 2003) are affected. This sequence of effects is also supported by previous studies from our group showing that 0.25 MAC sevoflurane alters resting brain perfusion in a non-homogeneous manner across several regions (Qiu et al., 2008a) and that it first affects the higher-order association areas (Ramani et al., 2007).

Together the results from this study suggest that BOLD functional connectivity reflects intrinsic properties of the brain and that the strength of the intrinsic connections can be modulated in a spatially dependent manner by anesthesia with the higher-order cognitive areas exhibiting the largest changes in connectivity at 0.5 MAC dose. 


\section{Acknowledgments}

We thank Karen Martin for technical assistance. This material is based on work supported by the National Institutes of Health (NIH) under grant NIH R01 NS052344-02.

\section{Appendix A. Supplementary data}

Supplementary data associated with this article can be found, in the online version, at doi:10.1016/j.neuroimage.2009.07.028.

\section{References}

Alkire, M.T., Haier, R.J., Fallon, J.H., 2000. Toward a unified theory of narcosis: brain imaging evidence for a thalamocortical switch as the neurophysiologic basis of anesthetic-induced unconsciousness. Conscious Cogn. 9, 370-386.

Alkire, M.T., Hudetz, A.G., Tononi, G., 2008. Consciousness and anesthesia. Science 322 876-880.

Alkire, M.T., Miller, J., Steven, L., 2005. General anesthesia and the neural correlates of consciousness. Progress in Brain Research. Elsevier, pp. 229-244. 596-597.

Antognini, J.F., Buonocore, M.H., Disbrow, E.A., Carstens, E., 1997. Isoflurane anesthesia blunts cerebral responses to noxious and innocuous stimuli: a fMRI study. Life Sci. 61. PL349-PL354.

ASA Task Force, 1999. Practice guidelines for preoperative fasting and the use of pharmacologic agents to reduce the risk of pulmonary aspiration: application to healthy patients undergoing elective procedures: a report by the American Society of Anesthesiologist Task Force on Preoperative Fasting. Anesthesiology 90, 896-905.

Beauchamp, M.S., 2005. Statistical criteria in fMRI studies of multisensory integration. Neuroinformatics 3, 93-113.

Biswal, B., Yetkin, F.Z., Haughton, V.M., Hyde, J.S., 1995. Functional connectivity in the motor cortex of resting human brain using echo-planar MRI. Magn. Reson. Med. 34 537-541.

Boly, M., Phillips, C., Tshibanda, L., Vanhaudenhuyse, A., Schabus, M., Dang-Vu, T.T., Moonen, G., Hustinx, R., Maquet, P., Laureys, S., 2008. Intrinsic brain activity in altered states of consciousness: how conscious is the default mode of brain function? Ann. N. Y. Acad. Sci. 1129, 119-129.

Boly, M., Tshibanda, L., Vanhaudenhuyse, A., Noirhomme, Q., Schnakers, C., Ledoux, D. Boveroux, P., Garweg, C., Lambermont, B., Phillips, C., Luxen, A., Moonen, G., Bassetti, C. Maquet, P., Laureys, S., 2009. Functional connectivity in the default network during resting state is preserved in a vegetative but not in a brain dead patient. Hum Brain Mapp 30 (8), 2393-2400.

Buckner, R.L., Andrews-Hanna, J.R., Schacter, D.L., 2008. The brain's default network Ann. N. Y. Acad. Sci. 1124, 1-38.

Cappe, C., Barone, P., 2005. Heteromodal connections supporting multisensory integration at low levels of cortical processing in the monkey. Eur. J. Neurosci. 22, 2886-2902.

Cordes, D., Haughton, V.M., Arfanakis, K., Carew, J.D., Turski, P.A., Moritz, C.H., Quigley, M.A., Meyerand, M.E., 2001. Frequencies contributing to functional connectivity in the cerebral cortex in "resting-state" data. AJNR Am. J. Neuroradiol. 22, 1326-1333.

Cordes, D., Haughton, V.M., Arfanakis, K., Wendt, G.J., Turski, P.A., Moritz, C.H., Quigley, M.A., Meyerand, M.E., 2000. Mapping functionally related regions of brain with functional connectivity MR imaging. AJNR Am. J. Neuroradiol. 21, 1636-1644.

De Luca, M., Smith, S., De Stefano, N., Federico, A., Matthews, P.M., 2005. Blood oxygenation level dependent contrast resting state networks are relevant to functional activity in the neocortical sensorimotor system. Exp. Brain Res. 167, $587-594$

Drummond, J.C., 1997. The lower limit of autoregulation: time to revise our thinking? Anesthesiology 86, 1431-1433.

Eckert, M.A., Kamdar, N.V., Chang, C.E., Beckmann, C.F., Greicius, M.D., Menon, V., 2008 A cross-modal system linking primary auditory and visual cortices: evidence from intrinsic fMRI connectivity analysis. Hum. Brain Mapp. 29, 848-857.

Fair, D.A., Cohen, A.L., Dosenbach, N.U.F., Church, J.A., Miezin, F.M., Barch, D.M., Raichle M.E., Petersen, S.E., Schlaggar, B.L., 2008. The maturing architecture of the brain's default network. Proc. Natl. Acad. Sci. U. S. A. 105, 4028-4032.

Fiset, P., Paus, T., Daloze, T., Plourde, G., Meuret, P., Bonhomme, V., Hajj-Ali, N., Backman, S.B., Evans, A.C., 1999. Brain mechanisms of propofol-induced loss of consciousness in humans: a positron emission tomographic study. J. Neurosci. 19, 5506-5513.

Fox, M.D., Corbetta, M., Snyder, A.Z., Vincent, J.L., Raichle, M.E., 2006. Spontaneous neuronal activity distinguishes human dorsal and ventral attention systems. Proc. Natl. Acad. Sci. U. S. A. 103, 10046-10051.

Fox, M.D., Snyder, A.Z., Vincent, J.L., Corbetta, M., Van Essen, D.C., Raichle, M.E., 2005 The human brain is intrinsically organized into dynamic, anticorrelated functional networks. Proc. Natl. Acad. Sci. U. S. A. 102, 9673-9678.

Franks, N.P., 2008. General anaesthesia: from molecular targets to neuronal pathways of sleep and arousal. Nat. Rev. Neurosci. 9, 370-386.

Fu, K.-M.G., Johnston, T.A., Shah, A.S., Arnold, L., Smiley, J., Hackett, T.A., Garraghty, P.E., Schroeder, C.E., 2003. Auditory cortical neurons respond to somatosensory stimulation. J. Neurosci 23, 7510-7515.

Glover, G.H., Li, T.-Q., Ress, D., 2000. Image-based method for retrospective correction of physiological motion effects in fMRI: RETROICOR. Magn. Reson. Med. 44, 162-167.
Greicius, M.D., Kiviniemi, V., Tervonen, O., Vainionpää, V., Alahuhta, S., Reiss, A.L., Menon, V., 2008. Persistent default-mode network connectivity during light sedation. Hum. Brain Mapp. 29, 839-847.

Greicius, M.D., Krasnow, B., Reiss, A.L., Menon, V., 2003. Functional connectivity in the resting brain: a network analysis of the default mode hypothesis. Proc. Natl. Acad. Sci. U. S. A. 100, 253-258

Greicius, M.D., Supekar, K., Menon, V., Dougherty, R.F., 2009. Resting-state functional connectivity reflects structural connectivity in the default mode network. Cereb. Cortex 19, 72-78.

Hampson, M., Driesen, N.R., Skudlarski, P., Gore, J.C., Constable, R.T., 2006a. Brain connectivity related to working memory performance. J. Neurosci. 26, 13338-13343.

Hampson, M., Tokoglu, F., Sun, Z., Schafer, R.J., Skudlarski, P., Gore, J.C., Constable, R.T., 2006b. Connectivity-behavior analysis reveals that functional connectivity between left BA39 and Broca's area varies with reading ability. Neurolmage 31, 513-519.

Hays, W.L., 1981. Statistics. 3rd ed. Holt, Rinehart, and Winston, New York.

Heinke, W., Fiebach, C.J., Schwarzbauer, C., Meyer, M., Olthoff, D., Alter, K., 2004. Sequential effects of propofol on functional brain activation induced by auditory language processing: an event-related functional magnetic resonance imaging study. Br. J. Anaesth. 92, 641-650.

Horovitz, S.G., Fukunaga, M., de Zwart, J.A., van Gelderen, P.C., Fulton, S.J., Balkin, T., Duyn, J.H., 2008. Low frequency BOLD fluctuations during resting wakefulness and light sleep: a simultaneous EEG-fMRI study. Hum. Brain Mapp. 29, 671-682.

Johnson, M.K., Raye, C.L., Mitchell, K.J., Touryan, S.R., Greene, E.J., Nolen-Hoeksema, S., 2006. Dissociating medial frontal and posterior cingulate activity during selfreflection. Soc. Cogn. Affect. Neurosci. 1, 56-64.

Kayser, C., Petkov, C.I., Augath, M., Logothetis, N.K., 2005. Integration of touch and sound in auditory cortex. Neuron $48,373-384$

Kayser, C., Petkov, C.I., Logothetis, N.K., 2008. Visual modulation of neurons in auditory cortex. Cereb. Cortex 18, 1560-1574.

Kerssens, C., Hamann, S., Peltier, S., Hu, X.P., Byas-Smith, M.G., Sebel, P.S., 2005. Attenuated brain response to auditory word stimulation with sevoflurane: a functional magnetic resonance imaging study in humans. Anesthesiology 103, 11-19.

Kiviniemi, V., Jauhiainen, J., Tervonen, O., Pääkkö, E., Oikarinen, J., Vainionpää, V. Rantala, H., Biswal, B., 2000. Slow vasomotor fluctuation in fMRI of anesthetized child brain. Magn. Reson. Med. 44, 373-378.

Kiviniemi, VJ. Haanpää, $\mathrm{H}$, Kantola, J-H. Jauhiainen, J., Vainionpää, V., Alahuhta, S. Tervonen, O., 2005. Midazolam sedation increases fluctuation and synchrony of the resting brain BOLD signal. Magn. Reson. Imaging 23, 531-537.

Lacadie, C.M., Fulbright, R.K., Rajeevan, N., Constable, R.T., Papademetris, X., 2008. More accurate Talairach coordinates for neuroimaging using non-linear registration. NeuroImage 42, 717-725.

Lakatos, P., Chen, C.-M., O'Connell, M.N., Mills, A., Schroeder, C.E., 2007. Neuronal oscillations and multisensory interaction in primary auditory cortex. Neuron 53 , 279-292.

Lancaster, J.L., Woldorff, M.G., Parsons, L.M., Liotti, M., Freitas, C.S., Rainey, L., Kochunov, P.V., Nickerson, D., Mikiten, S.A., Fox, P.T., 2000. Automated Talairach Atlas labels for functional brain mapping. Hum. Brain Mapp. 10, 120-131.

Laufs, H., Walker, M.C., Lund, T.E., 2007. 'Brain activation and hypothalamic functional connectivity during human non-rapid eye movement sleep: an EEG/fMRI study' its limitations and an alternative approach. Brain 130, e75.

Laureys, S., Boly, M., Maquet, P., 2006. Tracking the recovery of consciousness from coma. J. Clin. Invest $116,1823-1825$

Lowe, M.J., Mock, B.J., Sorenson, J.A., 1998. Functional connectivity in single and multislice echoplanar imaging using resting-state fluctuations. NeuroImage 7 , 119-132.

Lu, H., Zuo, Y., Gu, H., Waltz, J.A., Zhan, W., Scholl, C.A., Rea, W., Yang, Y., Stein, E.A., 2007. Synchronized delta oscillations correlate with the resting-state functional MRI signal. Proc. Natl. Acad. Sci. U. S. A. 104, 18265-18269.

Marcar, V.L., Loenneker, T., Strassle, A.E., Schwarz, U., Martin, E., 2004. What effect does measuring children under anesthesia have on the blood oxygenation leveldependent signal? A functional magnetic resonance imaging study of visual cortex. Pediatr. Res. 56, 104-110.

Martuzzi, R., Murray, M.M., Michel, C.M., Thiran, J.-P., Maeder, P.P., Clarke, S., Meuli, R.A., 2007. Multisensory interactions within human primary cortices revealed by BOLD dynamics. Cereb. Cortex 17, 1672-1679.

Meltzer, J.A., Constable, R.T., 2005. Activation of human hippocampal formation reflects success in both encoding and cued recall of paired associates. NeuroImage 24, 384-397.

Négyessy, L., Nepusz, T., Kocsis, L., Bazsó, F., 2006. Prediction of the main cortical areas and connections involved in the tactile function of the visual cortex by network analysis. Eur. J. Neurosci. 23, 1919-1930.

Nir, Y., Hasson, U., Levy, I., Yeshurun, Y., Malach, R., 2006. Widespread functional connectivity and fMRI fluctuations in human visual cortex in the absence of visual stimulation. Neurolmage 30,1313-1324.

Papademetris, X., Jackowski, A.P., Schultz, R.T., Staib, L.H., Duncan, J.S., 2004. Integrated intensity and point-feature nonrigid registration. Medical Image Computing and Computer-Assisted Intervention - MICCAI 2004, pp. 763-770.

Peltier, S., Stilla, R., Mariola, E., LaConte, S., Hu, X., Sathian, K., 2007. Activity and effective connectivity of parietal and occipital cortical regions during haptic shape perception. Neuropsychologia 45, 476-483.

Peltier, S.J., Kerssens, C., Hamann, S.B., Sebel, P.S., Byas-Smith, M., Hu, X., 2005. Functional connectivity changes with concentration of sevoflurane anesthesia. NeuroReport 16, 285-288

Plourde, G., Belin, P., Chartrand, D., Fiset, P., Backman, S.B., Xie, G., Zatorre, R.J., 2006. Cortical processing of complex auditory stimuli during alterations of consciousness with the general anesthetic propofol. Anesthesiology 104, 448-457. 
Qiu, M., Ramani, R., Swetye, M., Constable, R.T., 2008a. Spatial nonuniformity of the resting CBF and BOLD responses to sevoflurane: in vivo study of normal human subjects with magnetic resonance imaging. Hum. Brain Mapp. 29, 1390-1399.

Qiu, M., Ramani, R., Swetye, M., Rajeevan, N., Constable, R.T., 2008b. Anesthetic effects on regional CBF, BOLD, and the coupling between task-induced changes in CBF and BOLD: an fMRI study in normal human subjects. Magn. Reson. Med. 60, 987-996.

Ramani, R., Qiu, M., Constable, R.T., 2007. Sevoflurane 0.25 MAC preferentially affects higher order association areas: a functional magnetic resonance imaging study in volunteers. Anesth. Analg. 105, 648-655.

Ramani, R., Wardhan, R., 2008. Understanding anesthesia through functional imaging. Curr. Opin. Anaesthesiol. 21, 530-536.

Rekkas, P.V., Constable, R.T., 2005. Evidence that autobiographic memory retrieval does not become independent of the hippocampus: an fMRI study contrasting very recent with remote events. J. Cogn. Neurosci. 17, 1950-1961.

Rekkas, P.V., Constable, R.T., 2006. Hemodynamic retrieval intensity in hippocampus is decreased by pre-exposure to autobiographic test items. Brain Res. Bull. 70, 467-473.

Schlünzen, L., Vafaee, M.S., Cold, G.E., Rasmussen, M., Nielsen, J.F., Gjedde, A., 2004. Effects of subanaesthetic and anaesthetic doses of sevoflurane on regional cerebral blood flow in healthy volunteers. A positron emission tomographic study. Acta Anaesthesiol. Scand. 48, 1268-1276.

Schroeder, C.E., Lindsley, R.W., Specht, C., Marcovici, A., Smiley, J.F., Javitt, D.C., 2001. Somatosensory input to auditory association cortex in the macaque monkey. J. Neurophysiol. 85, 1322-1327.

Shannon, B.J., Buckner, R.L., 2004. Functional-anatomic correlates of memory retrieval that suggest nontraditional processing roles for multiple distinct regions within posterior parietal cortex. J. Neurosci. 24, 10084-10092.
Shehzad, Z., Kelly, A.M.C., Reiss, P.T., Gee, D.G., Gotimer, K., Uddin, L.Q., Lee, S.H Margulies, D.S., Roy, A.K., Biswal, B.B., Petkova, E., Castellanos, F.X., Milham, M.P., 2009. The Resting Brain: Unconstrained yet Reliable. Cereb. Cortex 19 (10), 2209-2229.

Shulman, G.L., Fiez, J.A., Corbetta, M., Buckner, R.L., Miezin, F.M., Raichle, M.E., Petersen, S.E., 1997. Common blood flow changes across visual tasks: II. Decreases in cerebral cortex. J. Cogn. Neurosci. 9, 648-663.

Smiley, JF, Hackett, TA Ulbert, I., Karmas, G, Lakatos, P, Javitt, D.C Schroeder, C.E., 2007. Multisensory convergence in auditory cortex, I. Cortical connections of the caudal superior temporal plane in macaque monkeys. J. Comp. Neurol. 502, 894-923.

Tracey, I., Mantyh, P.W., 2007. The cerebral signature for pain perception and its modulation. Neuron 55, 377-391.

Vahle-Hinz, C., Detsch, O., Siemers, M., Kochs, E., 2007. Contributions of GABAergic and glutamatergic mechanisms to isoflurane-induced suppression of thalamic somatosensory information transfer. Exp. Brain Res. 176, 159-172.

Vincent, J.L., Patel, G.H., Fox, M.D., Snyder, A.Z., Baker, J.T., Van Essen, D.C., Zempel, J.M., Snyder, L.H., Corbetta, M., Raichle, M.E., 2007. Intrinsic functional architecture in the anaesthetized monkey brain. Nature 447, 83-86.

Vincent, J.L., Snyder, A.Z., Fox, M.D., Shannon, B.J., Andrews, J.R., Raichle, M.E., Buckner R.L., 2006. Coherent spontaneous activity identifies a hippocampal-parietal memory network. J. Neurophysiol. 96, 3517-3531.

Wheeler, M.E., Buckner, R.L., 2004. Functional-anatomic correlates of remembering and knowing. Neurolmage 21, 1337-1349.

White, N.S., Alkire, M.T., 2003. Impaired thalamocortical connectivity in humans during general-anesthetic-induced unconsciousness. Neurolmage 19, 402-411.

Yu, C., Liu, Y., Li, J., Zhou, Y., Wang, K., Tian, L., Qin, W., Jiang, T., Li, K., 2008. Altered functional connectivity of primary visual cortex in early blindness. Hum. Brain Mapp. 29, 533-543. 